\title{
The Relationship between the Heat Disorder Incidence Rate and Heat Stress Indices at Yamanashi Prefecture in Japan
}

\author{
Shin Akatsuka, ${ }^{1}$ Tadashi Uno, ${ }^{2}$ and Masahiro Horiuchi ${ }^{2}$ \\ ${ }^{1}$ School of Systems Engineering, Kochi University of Technology, 185 Miyanokuchi, Tosayamada, Kami, Kochi 782-8502, Japan \\ ${ }^{2}$ Department of Human Environmental Science, Mount Fuji Research Institute, 5597-1 Kenmarubi, Kamiyoshida, \\ Fujiyoshida, Yamanashi 403-0005, Japan \\ Correspondence should be addressed to Shin Akatsuka; akatsuka.shin@kochi-tech.ac.jp
}

Received 10 September 2015; Accepted 27 March 2016

Academic Editor: Adel Hanna

Copyright (C) 2016 Shin Akatsuka et al. This is an open access article distributed under the Creative Commons Attribution License, which permits unrestricted use, distribution, and reproduction in any medium, provided the original work is properly cited.

In recent years, the risk of heat disorder in daily life has increased dramatically because the thermal environment has been deteriorating. The main objective of this study was to examine regional differences in the relationship between heat disorder incidence rate and heat stress indices at Yamanashi Prefecture, Japan. Daily maximum air temperature and daily maximum WBGT were used as heat stress indices in each region. Nonlinear regression analysis was used to examine the regional difference in the relationship between the heat disorder incidence rate and heat stress indices in each region. The heat disorder incidence rate was correlated with both indices of heat stress in all regions. However, the more appropriate heat stress index for heat disorder prevention differed among regions. The distributions of heat stress indices, such as the slope of regression curve and the temperature threshold, differed in each region, irrespective of the index used. Therefore, the criteria for thermal conditions for heat disorder prevention need to be determined for each region, considering the regional characteristics of the relationship between the heat disorder incidence rate and heat stress indices.

\section{Introduction}

In recent years, the thermal environment has been deteriorating because of global warming and the heat island phenomenon [1]. These contribute to increased heat stress, and the risk of heat disorder in daily life has also increased dramatically [2-4]. Previous studies have reported that the number of individuals affected by heat disorder was closely associated with air temperature and wet-bulb globe temperature (WBGT) [4-9]. Therefore, air temperature and WBGT have been used as heat stress indices for heat disorder prevention [10-13].

Daily maximum air temperature is a widely used predictive value in weather forecasting because it is a straightforward index of thermal condition [7]. It is also commonly used to set criteria for thermal conditions for heat disorder prevention. However, both the Japan Sports Association (JSA) and Japanese Society of Biometeorology (JSB) announced guidelines for the prevention of heat disorder in 1993 and in 2007 , respectively, and both organizations used WBGT as the heat stress index to set the criteria for thermal conditions [6]. This is because not only air temperature but also humidity and radiant heat are important factors determining the heat disorder incidence rate [14]; WBGT, which includes all three factors, is considered to be most informative index for the thermal conditions that indicates heat disorder probability [10] and is most widely used as the index of heat stress in the world [15]. Previous research has identified a stronger positive correlation between the heat disorder incidence rate and WBGT than the correlation with daily maximum air temperature and has suggested that the use of WBGT removes regional differences in the relationship between the heat stress index and the heat disorder incidence rate [11].

In a study conducted in Tokyo and Chiba City, Japan, Hoshi et al. [16] compared the relationship between the heat disorder incidence rate and daily maximum air temperature and that between the heat disorder incidence and WBGT at the time daily maximum air temperature was observed. The distribution of the daily maximum air temperature on the day of occurrence of heat disorder was lower in 
Chiba City than in Tokyo, but the distribution of WBGT at the time of daily maximum air temperature on the day of occurrence was similar [16]. This finding indicates that the use of WBGT could remove regional differences in the relationship between the heat disorder incidence rate and heat stress indices. However, the previous study was conducted in two megacities, both of which face the Pacific Ocean [16]. It remains unclear whether the use of WBGT could also remove regional differences in the relationship between the heat disorder incidence rate and heat stress index in inland regions. Indeed, Zhang et al. [17] reported that the importance of weather variables in predicting heatrelated mortality differed by cities. In addition, to offer helpful information for preventing heat disorder in inland region seems to have higher priority than in coastal regions because it was found that mortality due to heat disorder in internal regions is higher than that in the area along the Pacific Ocean [18].

Yamanashi Prefecture, which is located near the center of Honshu, the main island of Japan, is surrounded by high mountains and has a typical inland climate. Because the habitable regions in Yamanashi Prefecture cover a wide range of altitudes, air temperature and rainfall vary considerably among regions [19]. The objective of this study was to investigate regional differences in the relationship between the heat disorder incidence rate and heat stress indices in Yamanashi Prefecture and to examine whether the use of WBGT could remove these regional differences.

\section{Materials and Methods}

2.1. Study Area. Yamanashi Prefecture has a population of approximately 890,000 people and an area of $4,465 \mathrm{~km}^{2}, 78 \%$ of which is covered by forest [20]. In this study, Yamanashi Prefecture was divided into six regions according to the division used for fire services and weather forecasting: Kofu $(\mathrm{KF})$, Kyohoku (KH), Kyonan (KN), Kyoto (KT), Tobu (TB), and Fujigoko (FG) (Figure 1). Table 1 shows the mean values of daily mean, maximum, and minimum air temperatures from May 1 to October 31 for each year between 2009 and 2013. This study is based on the premise that each division of weather forecasting means the homogeneous region of climatic conditions and geographical characteristics.

2.2. Heat Stress Indices. In this study, daily maximum air temperature and daily maximum WBGT were used as the two indices of heat stress. The daily maximum air temperature was calculated from the hourly air temperature data from May 1 to October 31 for each year between 2009 and 2013. The hourly air temperature data were recorded by the Automated Meteorological Data Acquisition System (AMeDAS) of the Japan Meteorological Agency (JMA) [21].

The WBGT data were obtained from the Ministry of the Environment website for heat disorder prevention [22]. The WBGT was estimated hourly for each AMeDAS observational site using standard meteorological indices, such as drybulb temperature, relative humidity, solar radiation, and wind speed [23].
TABLE 1: The mean values of daily mean, maximum, and minimum air temperatures from May 1 to October 31 for each year between 2009 and 2013.

\begin{tabular}{lccc}
\hline & $\begin{array}{c}\text { Daily mean } \\
\text { air temp. } \\
\left({ }^{\circ} \mathrm{C}\right)\end{array}$ & $\begin{array}{c}\text { Daily max. } \\
\text { air temp. } \\
\left({ }^{\circ} \mathrm{C}\right)\end{array}$ & $\begin{array}{c}\text { Daily min. air } \\
\text { temp. } \\
\left({ }^{\circ} \mathrm{C}\right)\end{array}$ \\
\hline $\mathrm{KF}$ & $22.7 \pm 4.5$ & $27.9 \pm 5.2$ & $18.8 \pm 4.9$ \\
$\mathrm{KH}$ & $20.8 \pm 4.5$ & $25.8 \pm 5.1$ & $16.9 \pm 4.9$ \\
$\mathrm{KN}$ & $21.9 \pm 4.3$ & $26.9 \pm 4.8$ & $18.2 \pm 4.6$ \\
$\mathrm{KT}$ & $22.2 \pm 4.6$ & $27.6 \pm 5.3$ & $18.2 \pm 4.9$ \\
$\mathrm{~TB}$ & $20.7 \pm 4.6$ & $26.0 \pm 5.4$ & $16.4 \pm 4.8$ \\
$\mathrm{FG}$ & $17.7 \pm 4.6$ & $22.4 \pm 5.0$ & $13.6 \pm 5.0$ \\
\hline
\end{tabular}

Values are mean \pm standard deviation.

KF: Kofu, KH: Kyohoku, KT: Kyoto, KN: Kyonan, TB: Tobu, and FG: Fujigoko.

The daily maximum air temperature and daily maximum WBGT in each region were calculated as mean values using data from the AMeDAS observational site in each region (Figure 1).

2.3. Heat Disorder Incidence Rate. The heat disorder incidence rate for each region was assessed using the database of emergency transportation records for cases of heat disorder from May 1 to October 31 each year between 2009 and 2013. This database was created by the Disaster Prevention and Crisis Management Division of the Yamanashi Prefectural Government based on the records of emergency phone calls to fire department services.

The heat disorder incidence rate in each region is defined as the frequency of heat disorder per 100,000 individuals per day and is calculated using the following equation:

$$
R_{\mathrm{HDI}}=\frac{F_{\mathrm{HD}} \times 10^{5}}{\mathrm{POP} \times N_{\mathrm{HSI}}}
$$

where $F_{\mathrm{HD}}$ is the frequency of individuals transported for heat disorder in each region (persons), POP is the population in each region (persons), and $N_{\mathrm{HSI}}$ is the number of days with respect to the class interval of heat stress indices in each region (days). The population in each region was calculated using demographics provided by the Yamanashi Prefectural Government (Table 2). The frequency of individuals transported for heat disorder was assembled with respect to the class interval of heat stress indices, which follows the procedure of previous studies $[16,24]$.

2.4. Data Analysis. The relationship between heat disorder incidence rate and heat stress indices was examined with a constant class interval width of heat stress indices among regions, that is, $1^{\circ} \mathrm{C}$. In addition, because the class interval width of WBGT equivalent to $1^{\circ} \mathrm{C}$ in air temperature is thought to vary in each region, the relationship for WBGT was also calculated using different class interval widths.

Regression formulas were derived by the nonlinear least squares method using heat disorder incidence rate and the 


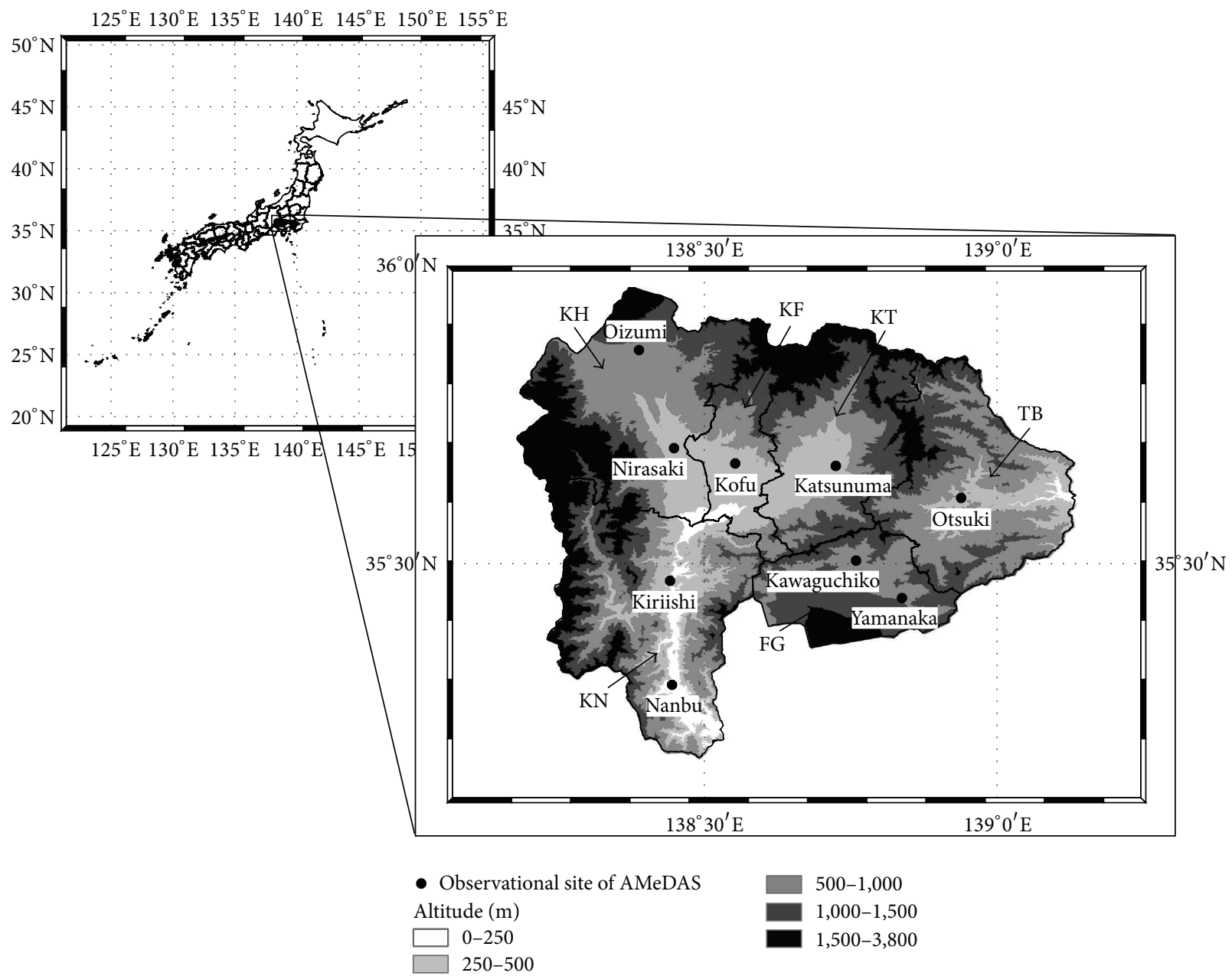

Figure 1: Map showing the location of Yamanashi Prefecture and the regions used for analysis (KF: Kofu; KH: Kyohoku; KT: Kyoto; KN: Kyonan; TB: Tobu; FG: Fujigoko).

TABLE 2: The daytime population in each region. Abbreviations are the same as those in Table 1.

\begin{tabular}{lc}
\hline & Daytime population (persons) \\
\hline KF & 328,023 \\
KH & 159,952 \\
KN & 129,906 \\
KT & 53,597 \\
TB & 86,248 \\
FG & 97,128 \\
\hline
\end{tabular}

median of each class for both heat stress indices. Exponentialtype functions were used as the regression formulas because previous studies reported that the heat disorder incidence rate increases exponentially with increasing air temperature and WBGT $[6,7]$. In addition, these exponential-type functions were fitted up to the peak of heat disorder incidence rate, because the heat disorder incidence rate in the class of higher peak temperature seems to be strongly influenced by factors other than meteorological conditions. The heat disorder incidence rate in the class of higher peak temperature is smaller because people spontaneously take measures against heat disorder in relentless heat conditions, such as using air conditioning, refraining from exercise and working outdoors, taking frequent breaks, and staying adequately hydrated [24].

To investigate regional differences in the relationship between heat disorder incidence rate and heat stress indices in Yamanashi Prefecture using the values of heat stress indices, the temperature threshold of the heat stress indices was calculated. The temperature threshold is the value when the heat disorder incidence rate equals 1 (person/100,000 persons/day) using the regression equation derived from the relationship between heat disorder incidence rate and heat stress indices.

2.5. Statistical Analysis. Nonlinear regression analysis was used to examine the relationship between the heat disorder incidence rate $\left(R_{\mathrm{HDI}}\right)$ and heat stress indices in each region. In addition, to determine the class interval width of heat stress indices in each region, simple linear regression analysis 
between air temperature and WBGT was carried out. A $p$ value $<0.05$ was considered to be statistically significant.

\section{Results}

3.1. Constant Class Interval Width of Heat Stress Indices. Figures 2 and 3 show the relationships between heat disorder incidence rate and daily maximum air temperature and daily maximum WBGT, respectively, using a constant class interval width (i.e., $1^{\circ} \mathrm{C}$ ) for each region. The distribution of both heat stress indices against the heat disorder incidence rate varied among regions. The coefficient of regression curve for each region also varied for both heat stress indices. In particular, the distribution in the FG region was lower than that in other regions, and the regression curve for this region increased more sharply compared with that of other regions. The coefficient of regression curve for FG was approximately 0.65 for daily maximum air temperature and approximately 0.67 for daily maximum WBGT, while for other regions the values were $<0.35$ for daily maximum air temperature and $<0.55$ for daily maximum WBGT. The heat disorder incidence rate was correlated with both heat stress indices in all regions. However, some regions ( $\mathrm{KH}, \mathrm{KN}$, and FG) showed a stronger correlation between heat disorder incidence rate and daily maximum air temperature than daily maximum WBGT, while others (KF, KT, and TB) showed a stronger correlation between heat disorder incidence rate and daily maximum WBGT than daily maximum air temperature.

\subsection{Regression Analysis between Air Temperature and WBGT.} Figure 4 shows the relationship between air temperature at daily maximum WBGT and daily maximum WBGT. There was a strong positive correlation between them in all six regions. According to the slope of the regression line in each region, the class interval width of daily maximum WBGT equivalent to $1^{\circ} \mathrm{C}$ in air temperature was approximately $0.7-$ $0.8^{\circ} \mathrm{C}$. This value agreed closely with the results of a previous study [25].

\subsection{WBGT Using Various Class Interval Widths. Figure 5} shows the relationship between heat disorder incidence rate and daily maximum WBGT using various class interval widths. The coefficients of determination in all regions, except $\mathrm{KN}$, were smaller than those with a class interval width of $1^{\circ} \mathrm{C}$. The distribution of the daily maximum WBGT against the heat disorder incidence rate varied among regions and the variability in the coefficient of regression curves among regions with various class interval widths was greater compared with that among regions with constant class interval width (Figures 3 and 5).

3.4. Temperature Thresholds. Table 3 shows the temperature thresholds for heat stress indices in each region. The range of the temperature threshold was $7.0^{\circ} \mathrm{C}$ for daily maximum air temperature, $4.2^{\circ} \mathrm{C}$ for daily maximum WBGT with a constant class interval width, and $3.5^{\circ} \mathrm{C}$ for daily maximum WBGT with various class interval widths.

\section{Discussion}

The results of this study show that the heat disorder incidence rate was correlated with each heat stress index in all regions, but the more appropriate heat stress index for heat disorder prevention differed among regions. In addition, both the distributions of the heat stress indices against heat disorder incidence rate and the temperature threshold of heat stress indices varied among regions, regardless of both heat stress indices and class interval width.

Ono [24] reported that daily maximum WBGT was more closely associated with heat disorder incidence than daily maximum air temperature. However, our results showed a stronger relationship between heat disorder incidence rate and daily maximum air temperature than daily maximum WBGT in some regions and therefore were not in agreement with those of a previous study [24]. One reason for this discrepancy possibly relates to the class interval width of heat stress indices. In the previous study, the variability of frequency in each class was removed by setting the class interval width of heat stress indices at $1^{\circ} \mathrm{C}$, and then there was a strong positive correlation between heat disorder incidence rate and daily maximum WBGT [24]. On the other hand, in our study, the variability of frequency in each class increased in some regions when the class interval width of WBGT was $1^{\circ} \mathrm{C}$, and then the heat disorder incidence rate showed a stronger relationship to daily maximum air temperature than to daily maximum WBGT. Therefore, variability in the relationship between heat disorder incidence rate and heat stress indices, which was shown by the coefficients of determination, may depend on the class interval width.

In Yamanashi Prefecture, both the distribution of the heat stress indices against the heat disorder incidence rate and the temperature threshold of heat stress indices in each region differed regardless of the heat stress index used and the class interval width. In particular, the difference between the KF and FG regions, where the mean air temperature differed by approximately $5^{\circ} \mathrm{C}$, was only slightly reduced using daily maximum WBGT as the heat stress index for heat disorder incidence rate to prevent heat disorder. This indicates that the use of WBGT cannot effectively remove regional differences in the relationship between heat disorder incidence rate and heat stress indices in Yamanashi Prefecture. The FG region is cooler region and summer resort in Yamanashi Prefecture. A lot of young people visit for training camps in every summer season, and heat disorders often occur among them. This is the distinguishing characteristic of heat disorder incidence in FG region [25]. Thus the difference of meteorological condition may cause the difference of regional characteristics, such as demographic composition and socioeconomic condition. In addition, it is suggested that because the regional characteristics of heat disorder incidence depend on not only the meteorological conditions but also the major industry in each region, the use of WBGT cannot remove regional differences in the relationship between heat disorder incidence rate and heat stress indices.

Currently, there are two guidelines for the prevention of heat disorder in Japan, the JSA and JAB guidelines. The 


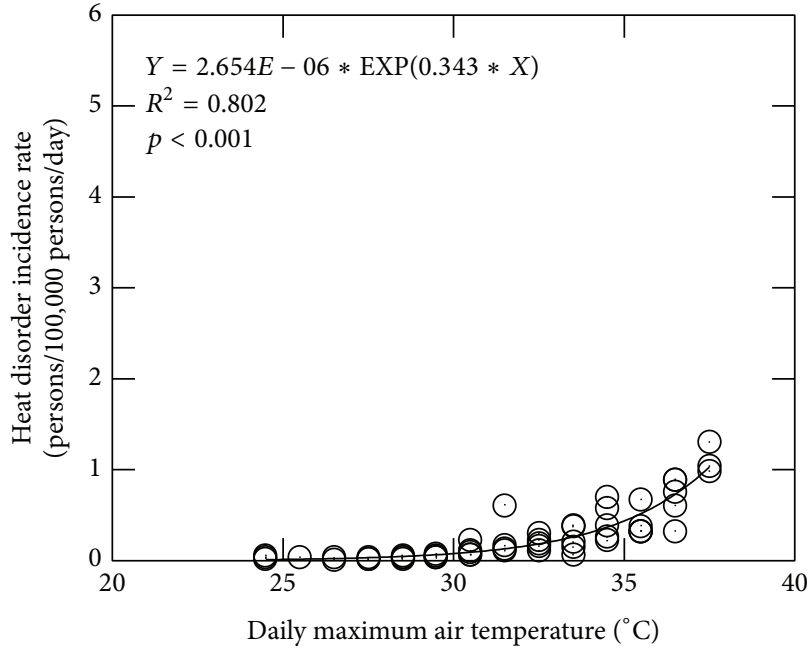

(a) $\mathrm{KF}$

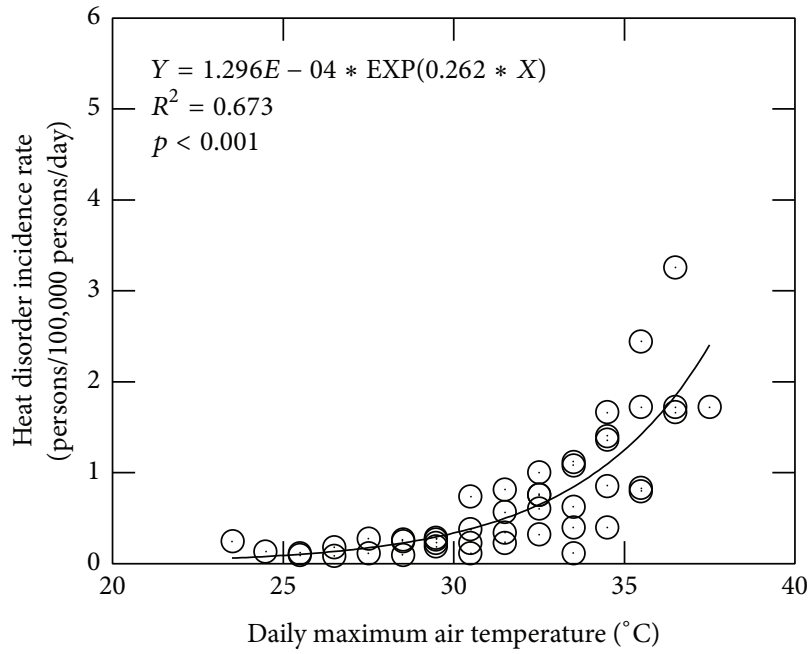

(c) $\mathrm{KN}$

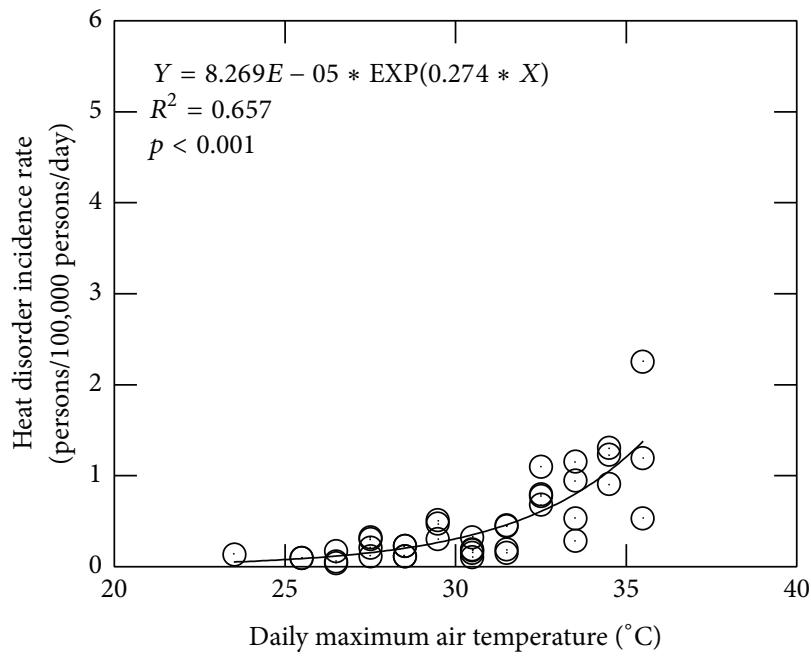

(e) TB

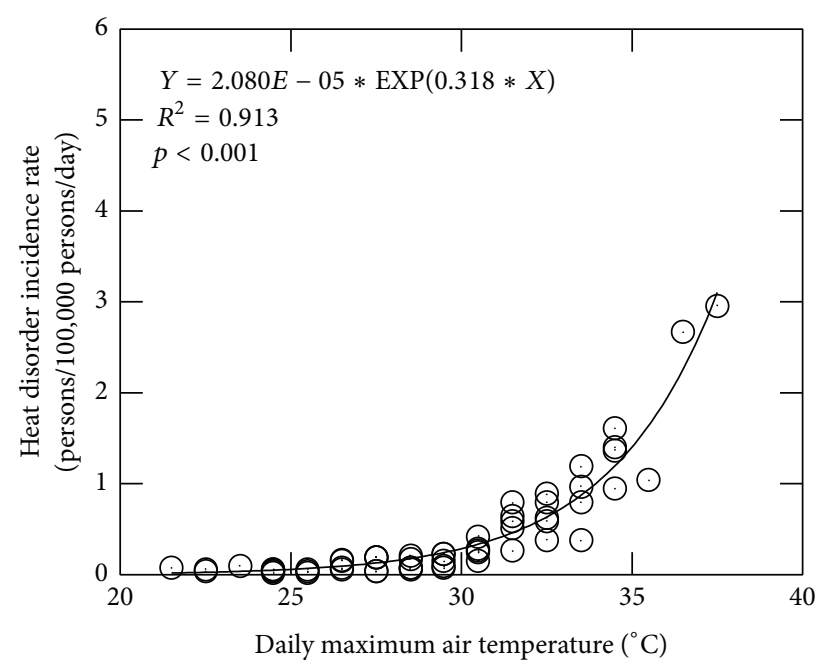

(b) $\mathrm{KH}$

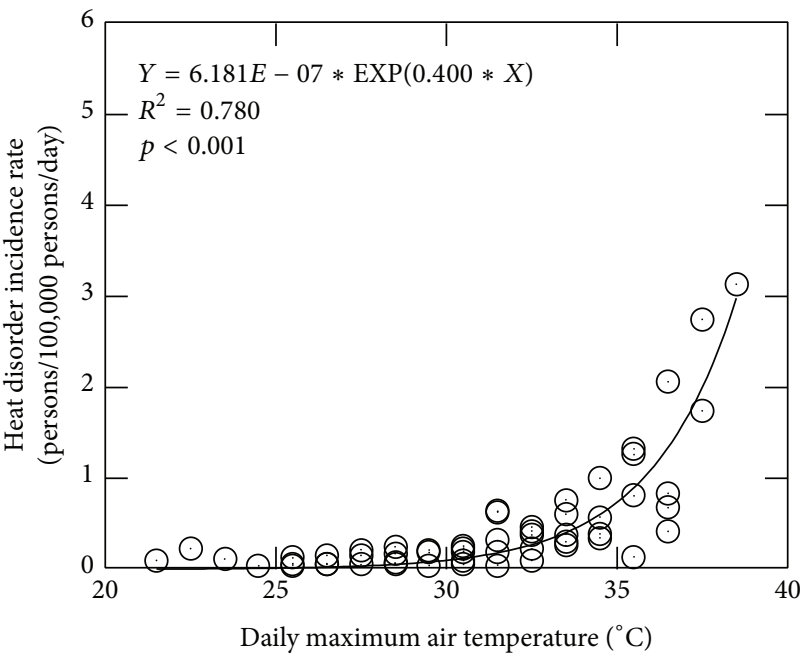

(d) KT

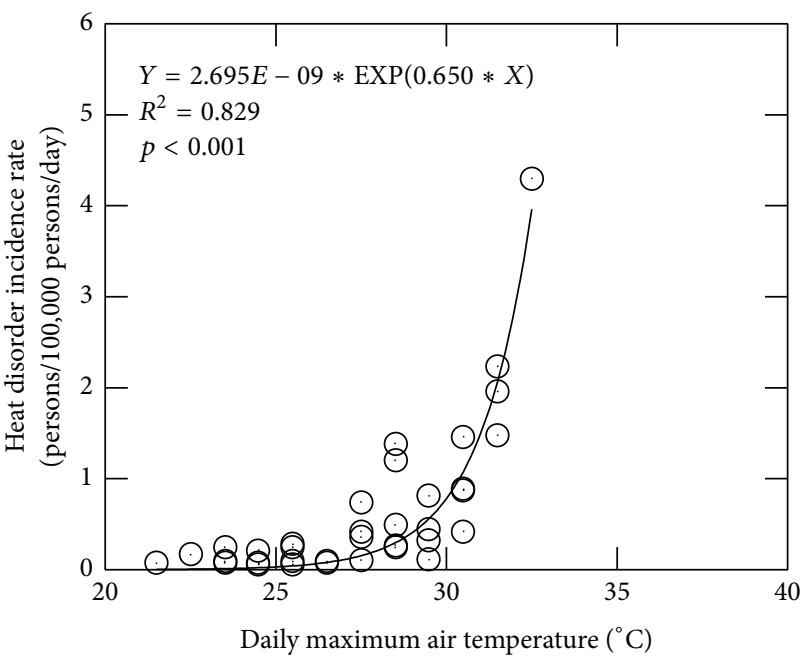

(f) FG

FIGURE 2: The relationship between heat disorder incidence rate and daily maximum air temperature in each region. The class interval width of daily maximum air temperature is $1^{\circ} \mathrm{C}$. The heat disorder incidence rate means the frequency of heat disorder per 100,000 individuals per day. The lines are the exponential regression lines. Abbreviations are the same as those in Figure 1. 


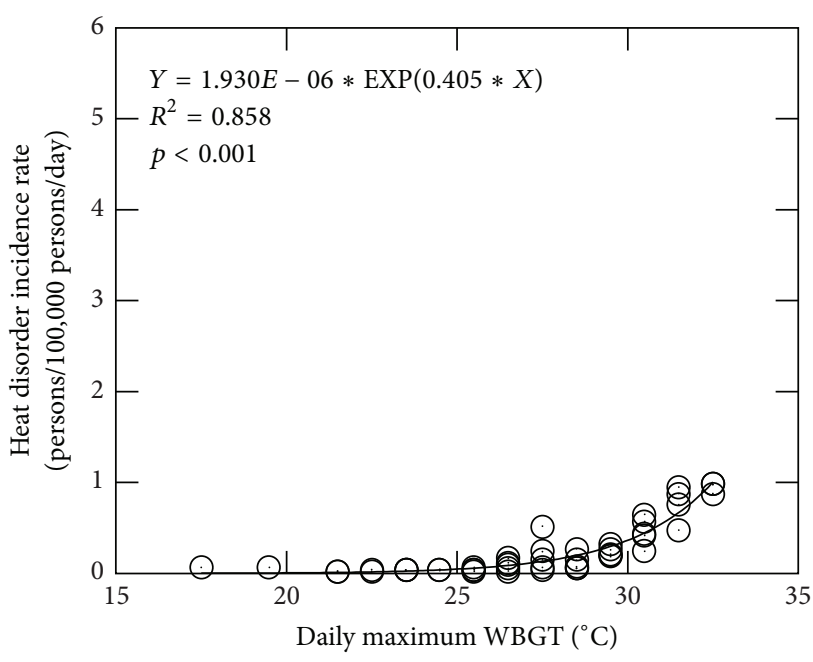

(a) $\mathrm{KF}$

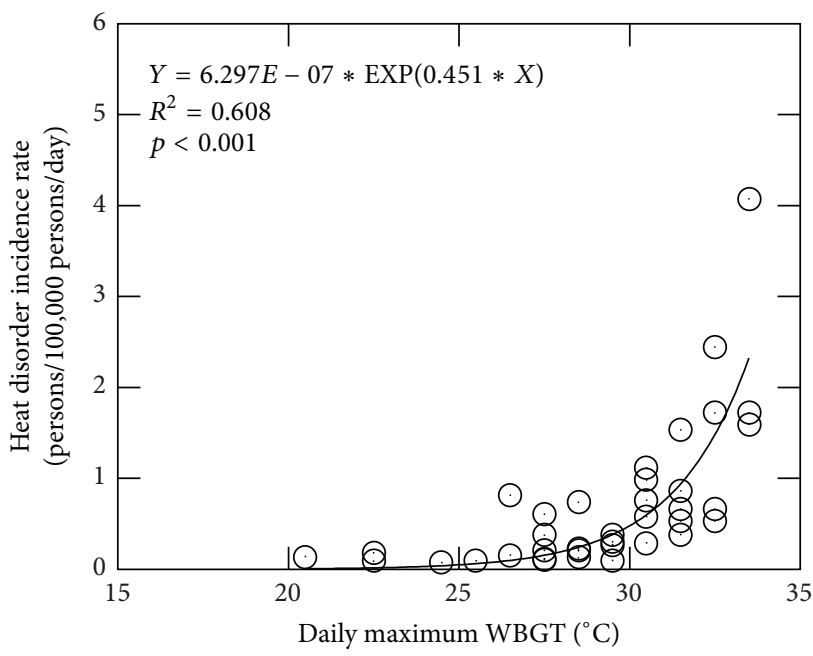

(c) $\mathrm{KN}$

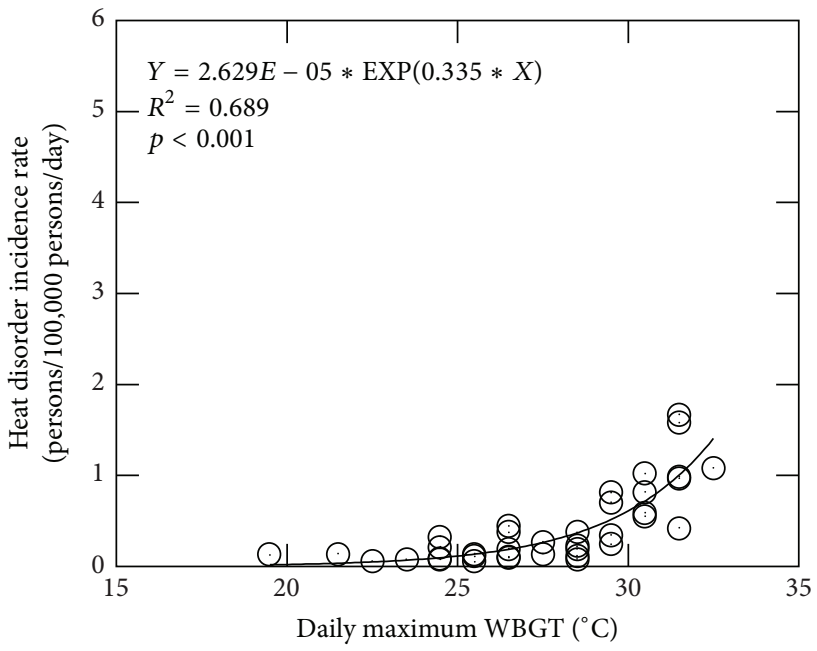

(e) TB

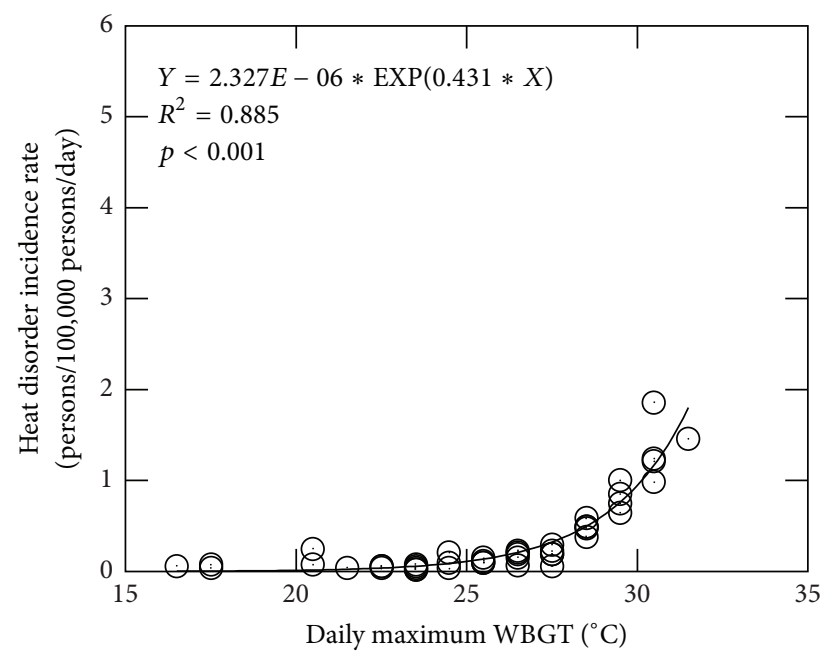

(b) $\mathrm{KH}$

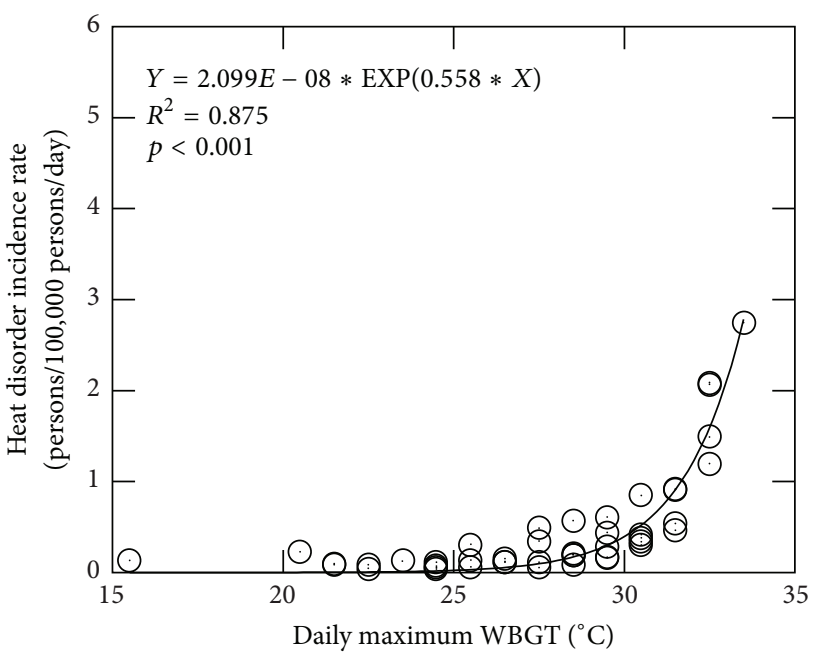

(d) $\mathrm{KT}$

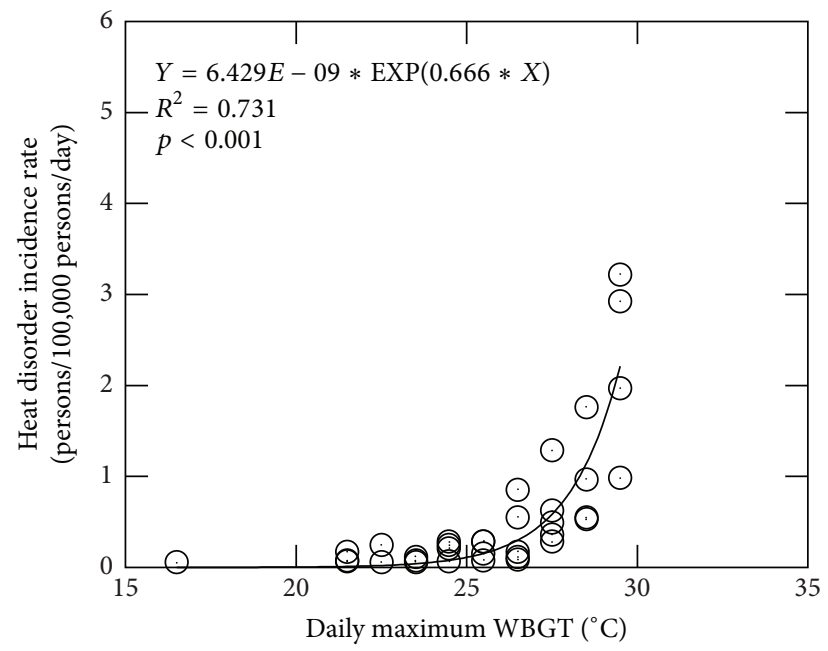

(f) FG

FIGURE 3: The relationship between heat disorder incidence rate and daily maximum WBGT in each region. The class interval width of daily maximum WBGT is $1^{\circ} \mathrm{C}$. The heat disorder incidence rate means the frequency of heat disorder per 100,000 individuals per day. The lines are the exponential regression lines. Abbreviations are the same as those in Figure 1. 


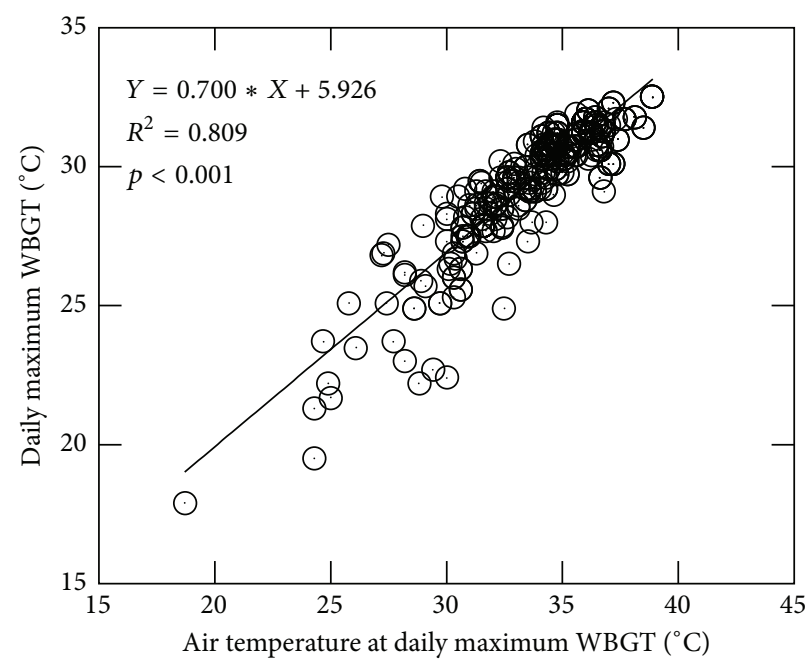

(a) $\mathrm{KF}$

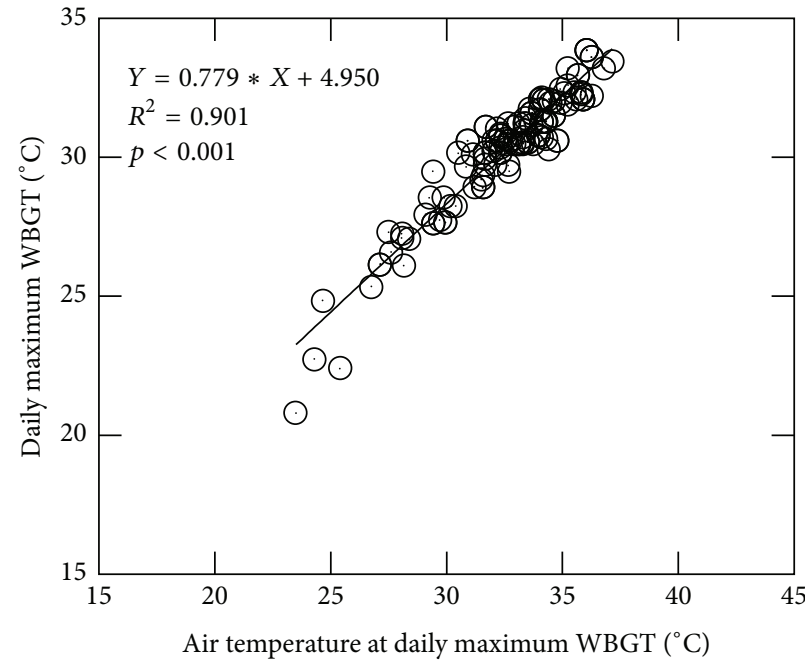

(c) $\mathrm{KN}$

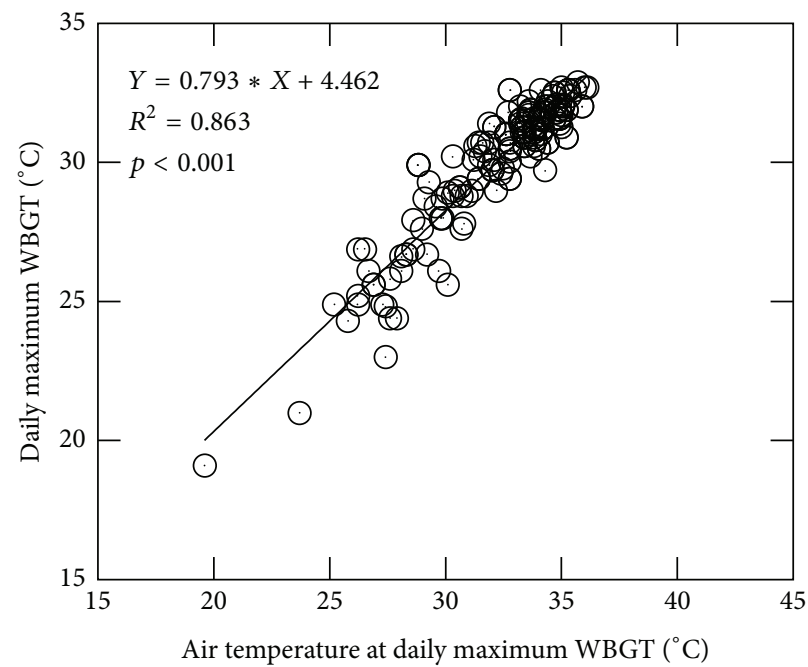

(e) $\mathrm{TB}$

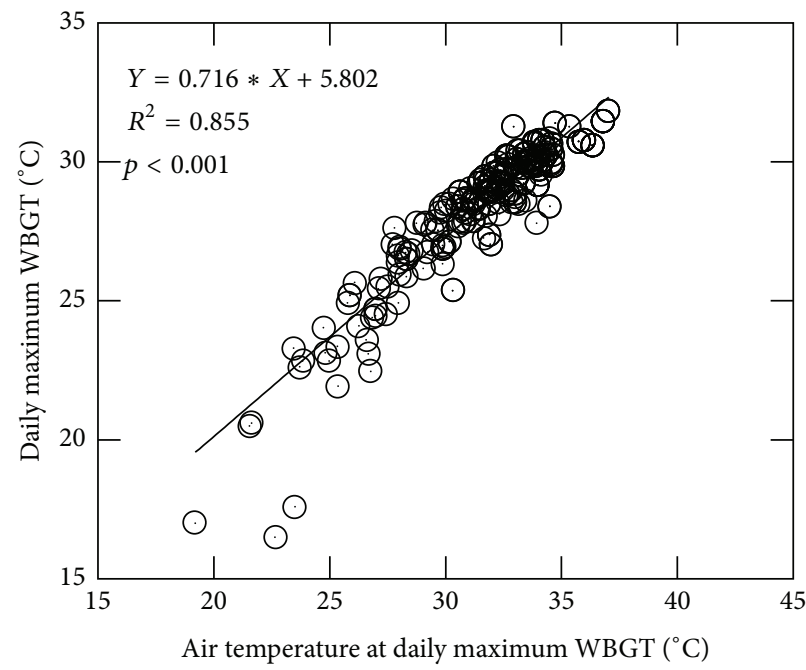

(b) $\mathrm{KH}$

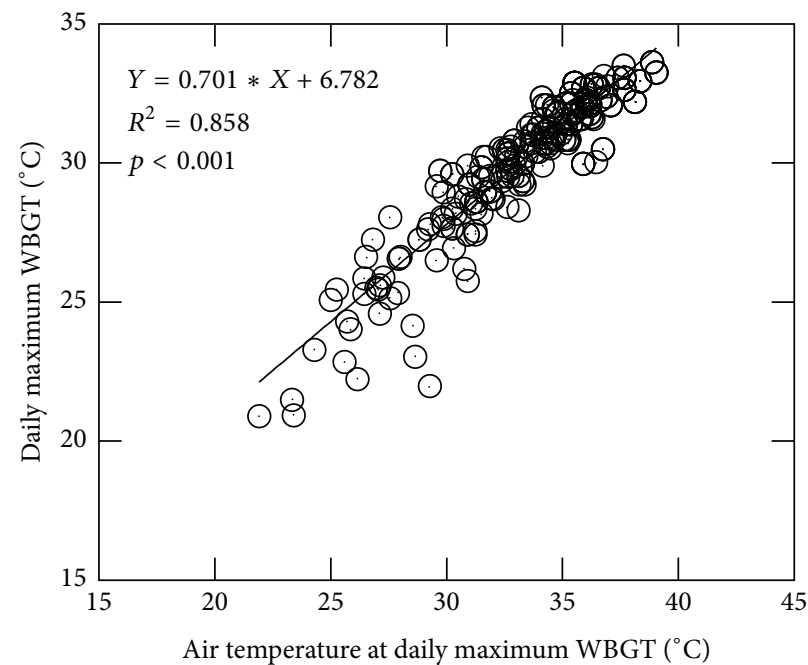

(d) $\mathrm{KT}$

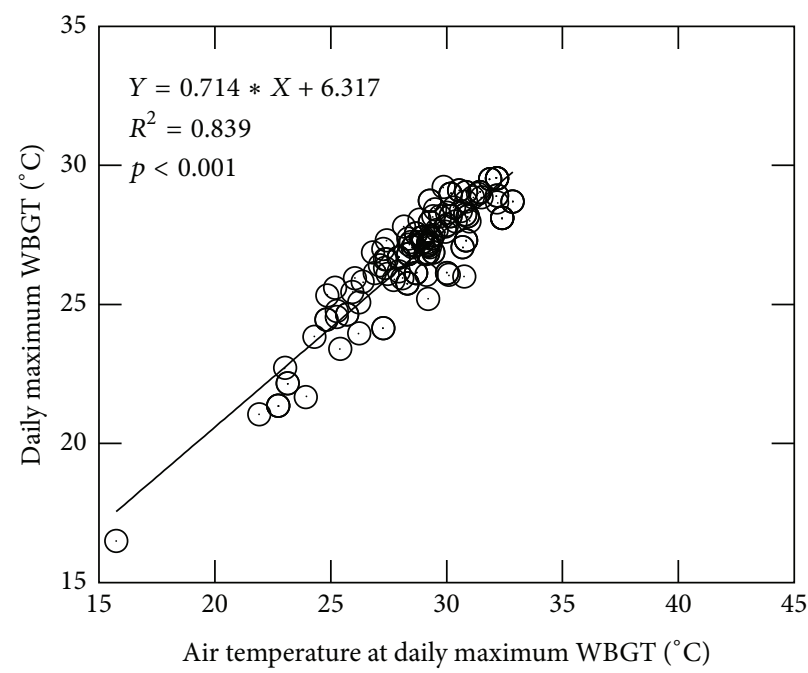

(f) FG

FIGURE 4: The relationship between air temperature at daily maximum WBGT and daily maximum WBGT. The lines are the linear regression lines. Abbreviations are the same as those in Figure 1. 


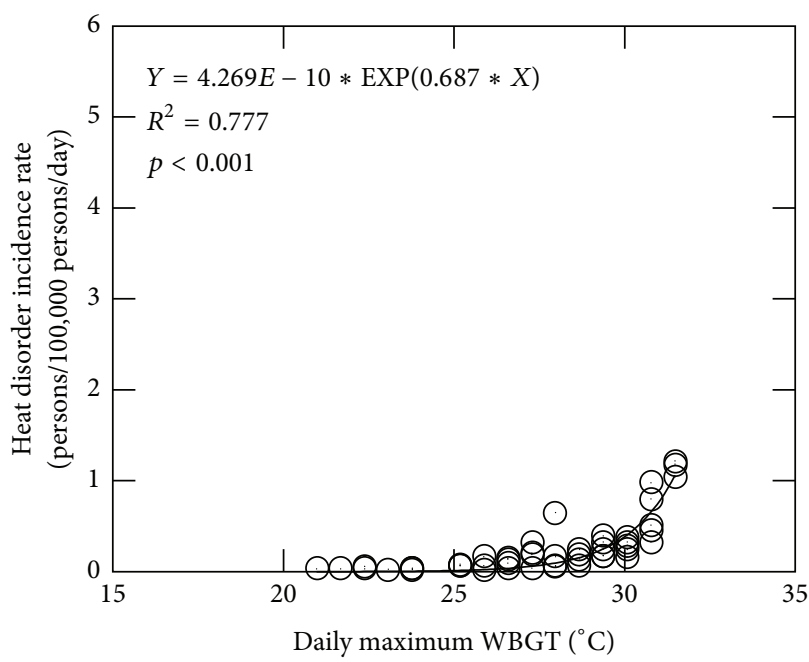

(a) $\mathrm{KF}$

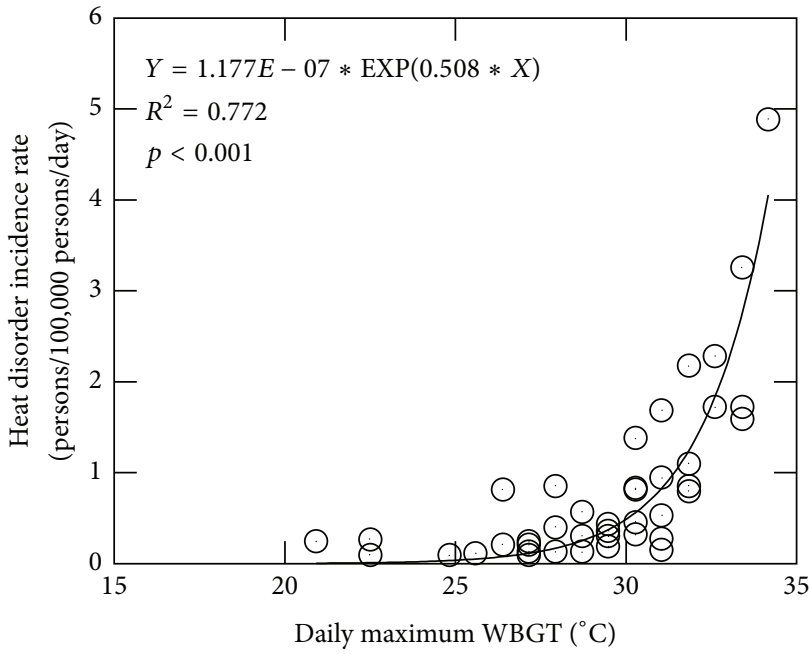

(c) $\mathrm{KN}$

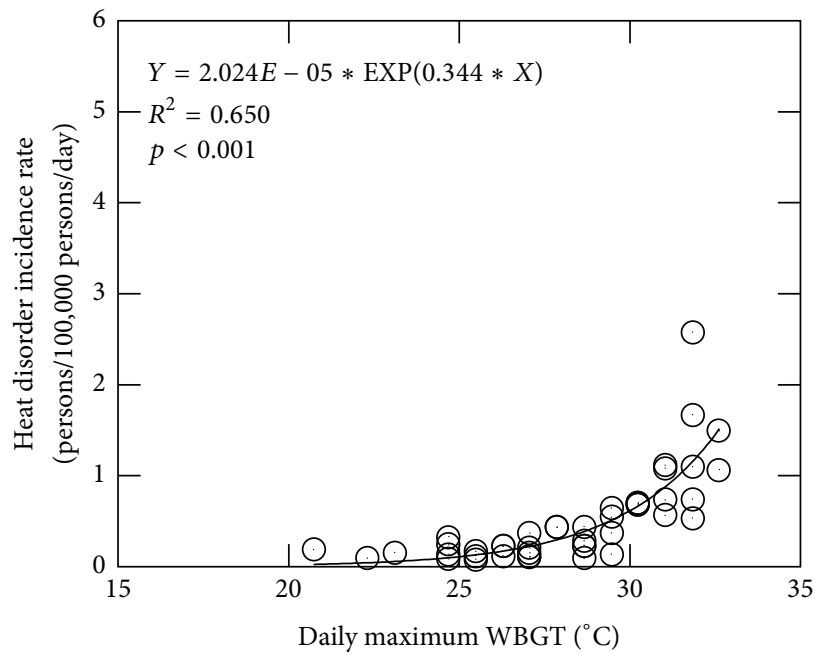

(e) TB

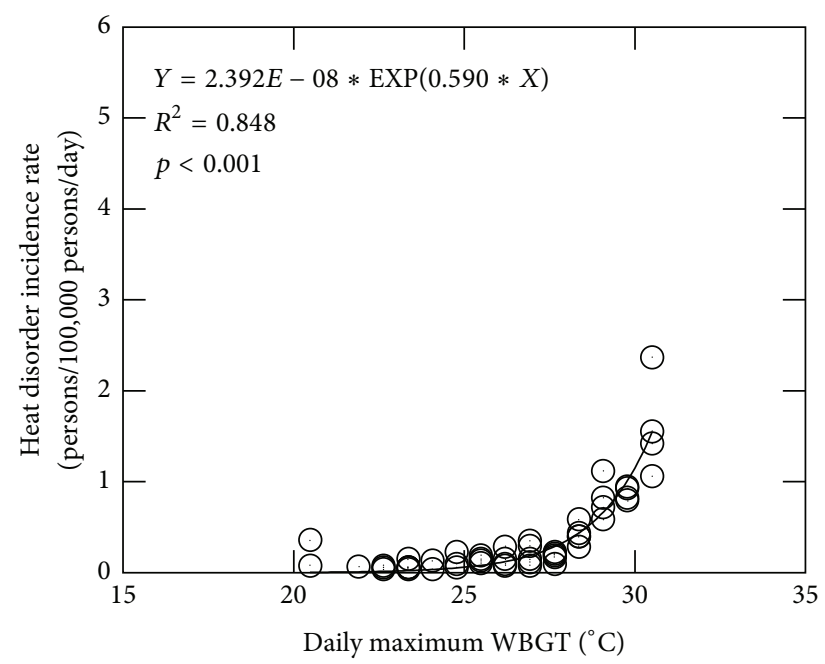

(b) $\mathrm{KH}$

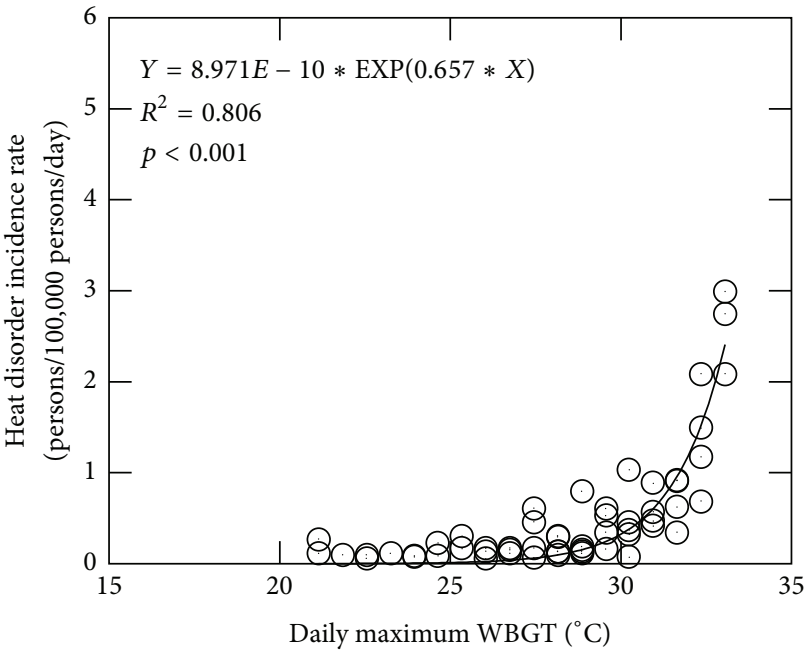

(d) $\mathrm{KT}$

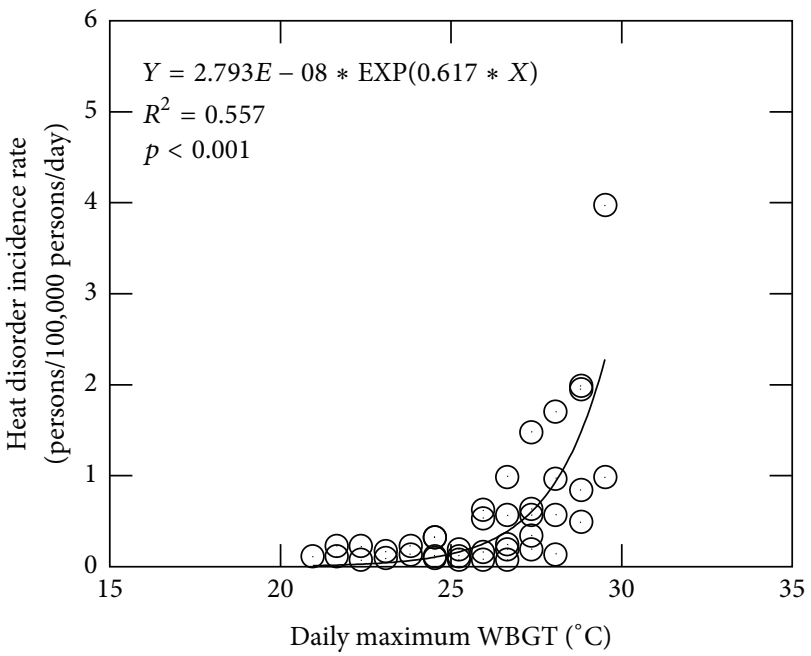

(f) FG

FIGURE 5: The relationship between heat disorder incidence rate and the daily maximum WBGT using class interval width of heat stress indices in each region that was derived from the simple linear regression analysis between air temperature at daily maximum WBGT and daily maximum WBGT. The heat disorder incidence rate means the frequency of heat disorder per 100,000 individuals per day. The lines are the exponential regression lines. Abbreviations are the same as those in Figure 1. 
TABLE 3: The temperature thresholds of heat stress indices in each region. Abbreviations are the same as those in Table 1.

\begin{tabular}{lccc}
\hline Heat stress indices & $\begin{array}{c}\text { Daily max. air temp. } \\
\left({ }^{\circ} \mathrm{C}\right)\end{array}$ & $\begin{array}{c}\text { Daily max. WBGT } \\
\left({ }^{\circ} \mathrm{C}\right)\end{array}$ & $\begin{array}{c}\text { Daily max. WBGT } \\
\left({ }^{\circ} \mathrm{C}\right)\end{array}$ \\
\hline Class interval width & Const. ${ }^{\mathrm{a}}$ & Const. $^{\mathrm{a}}$ & Various $^{\mathrm{b}}$ \\
$\mathrm{KF}$ & 37.4 & 32.5 & 31.4 \\
$\mathrm{KH}$ & 33.9 & 30.1 & 29.8 \\
$\mathrm{KN}$ & 34.2 & 31.6 & 31.4 \\
$\mathrm{KT}$ & 35.7 & 31.7 & 31.7 \\
$\mathrm{~TB}$ & 34.3 & 31.5 & 31.4 \\
FG & 30.4 & 28.3 & 28.2 \\
\hline
\end{tabular}

${ }^{\mathrm{a}}$ The class interval width of the heat stress index is $1^{\circ} \mathrm{C}$.

${ }^{b}$ The class interval width of the heat stress index was calculated from the regression equation derived from the relationship between air temperature at daily maximum WBGT and daily maximum WBGT.

criteria for thermal conditions for heat disorder prevention in the guidelines are very similar, and they are based on the supposition that WBGT could remove regional differences [11]. The guidelines set the following criteria for thermal conditions for heat disorder prevention based on WBGT: threat of heat disorder, $>31^{\circ} \mathrm{C}$ WBGT; severe warning, $28-31^{\circ} \mathrm{C}$ WBGT; warning, $25-28^{\circ} \mathrm{C}$ WBGT; caution, $21-25^{\circ} \mathrm{C}$ WBGT; and almost safe, $<21^{\circ} \mathrm{C}$ WBGT $[10,11]$. However, we previously reported that, in Yamanashi Prefecture, the regional characteristics of heat disorder incidence rate depended on not only the meteorological conditions in each region but also the major industry in each region [26]. Other studies also reported that the vulnerability and adaptation of human health to climate change were likely to be influenced by a combination of demographic composition, urban morphology, and socioeconomic conditions $[27,28]$. These previous studies indicate that heat disorder incidence rate is likely to depend not only on the meteorological conditions in each region but also on the regional characteristics, such as demographic composition and socioeconomic conditions [17, 2629]. In addition, this study indicates that it may be difficult to remove regional differences in heat disorder incidence rate to prevent heat disorder in Yamanashi Prefecture, even if daily maximum WBGT is used as the heat stress index. Zhang et al. [17] reported that apparent temperature appeared to be the most robust predictor of heat-related mortality in four cites of United States, though it must differ by cities. Therefore, it is important to use conventional guidelines for taking measures against heat disorder, and the criteria for thermal conditions for heat disorder prevention should be determined in each region by considering the regional characteristics in the relationship between heat disorder incidence rate and heat stress indices.

Our study has limitations in the analysis. First, we used the database of emergency transportation records for cases of heat disorder. We previously indicated the possible presence of regions where peoples do not tend to call an ambulance even if they get heat disorders in Yamanashi Prefecture [26]. Therefore, we require consideration of the patients who went to hospital by themselves in further study. Second, we aggregated the daily data of heat stress indices and heat disorder incidence and did not consider lag effects, because the procedure of this study followed that of the previous studies which evidence the guidelines for the prevention of heat disorder in Japan. However, a number of studies of temperature on mortality have taken into account the lag effects because "it has been increasingly recognized that the current day's mortality often derived from exposure to the current day's, or several previous days', even weeks' temperatures" $[30,31]$. Therefore, we should analyze the relationship between the heat disorder incidence rate and heat stress indices on a daily basis and consider the lag effects, but we followed the procedure of previous studies because one of the aims of this study is to examine where the finding of the previous studies can apply to Yamanashi Prefecture. However, in order to offer the conventional guidelines for taking measures against heat disorder, further studies should explore the lag effects of heat stress indices on heat disorder incidence.

\section{Conclusions}

In this study, we examined regional differences in the relationship between heat disorder incidence rate and heat stress indices at Yamanashi Prefecture, Japan. In addition, we examined whether use of WBGT index could remove these regional differences. The heat disorder incidence rate was correlated with both daily maximum air temperature and daily maximum WBGT in all regions. However, the more appropriate heat stress index for heat disorder prevention differed among regions. The distributions of heat stress indices, such as the slope of regression curve and the temperature threshold, differed in each region, irrespective of the index used. These results suggest that it may be difficult to completely remove regional differences in the heat disorder incidence rate to prevent heat disorder in Yamanashi Prefecture, even if daily maximum WBGT is used as the heat stress index. Therefore, the criteria for thermal conditions for heat disorder prevention need to be determined for each region, considering the regional characteristics of the relationship between the heat disorder incidence rate and heat stress indices. 


\section{Appendix}

\section{WBGT Estimation Equation}

Ono and Tonouchi [23] proposed a WBGT estimation equation using standard meteorological indices, such as drybulb temperature $\left(T_{a}\right)$, relative humidity $(\mathrm{RH})$, solar radiation (SR), and wind speed (WS). The WBGT estimation equation is defined as follows:

$$
\begin{aligned}
\mathrm{WBGT}= & 0.735 \times \mathrm{T}_{a}+0.0374 \times \mathrm{RH}+0.00292 \times T_{a} \\
& \times \mathrm{RH}+7.619 \times \mathrm{SR}-4.557 \times \mathrm{SR}^{2} \\
& -0.0572 \times \mathrm{WS}-4.064 .
\end{aligned}
$$

The WBGT could be estimated with $1.0^{\circ} \mathrm{C}$ or less estimation error with $98.3 \sim 99.8 \%$ confidence for six cities in Japan and for three years, 2007-2009.

\section{Competing Interests}

The authors declare that they have no conflict of interests.

\section{Acknowledgments}

This work was partly supported by JSPS KAKENHI Grant no. 25740030. This study does not include human participants.

\section{References}

[1] G. A. Meehl and C. Tebaldi, "More intense, more frequent, and longer lasting heat waves in the 21st century," Science, vol. 305, no. 5686, pp. 994-997, 2004.

[2] R. S. Kovats and K. L. Ebi, "Heatwaves and public health in Europe," European Journal of Public Health, vol. 16, no. 6, pp. 592-599, 2006.

[3] M. Poumadère, C. Mays, S. L. Mer, and R. Blong, "The 2003 heat wave in France: dangerous climate change here and now," Risk Analysis, vol. 25, no. 6, pp. 1483-1494, 2005.

[4] L. Bai, G. Ding, S. Gu et al., "The effects of summer temperature and heat waves on heat-related illness in a coastal city of China, 2011-2013," Environmental Research, vol. 132, pp. 212-219, 2014.

[5] J. S. Golden, D. Hartz, A. Brazel, G. Luber, and P. Phelan, "A biometeorology study of climate and heat-related morbidity in Phoenix from 2001 to 2006," International Journal of Biometeorology, vol. 52, no. 6, pp. 471-480, 2008.

[6] M. Tonouchi, "Japanese summer and heat disorder," Japanese Journal of Clinical Medicine, vol. 70, no. 6, pp. 981-985, 2012 (Japanese).

[7] S. Asanuma, C. Liang, and M. Ando, "Impact assessment of heat stress on population health in Japan and China," Global Environmental Research, vol. 11, pp. 39-44, 2007.

[8] W. T. Piver, M. Ando, Y. Frank, and C. J. Portier, “Temperature and air pollution as risk factors for heat stroke in Tokyo, July and August 1980-1995," Environmental Health Perspectives, vol. 107, no. 11, pp. 911-916, 1999.

[9] N. Miyatake, N. Sakano, and S. Murakami, "The relation between ambulance transports stratified by heat stroke and air temperature in all 47 prefectures of Japan in August, 2009: Ecological study," Environmental Health and Preventive Medicine, vol. 17, no. 1, pp. 77-80, 2012.
[10] M. Asayama, "Guideline for the prevention of heat disorder in Japan," Global Environmental Research, vol. 13, pp. 19-25, 2009.

[11] Y. Inaba and M. Asayama, "The outline of 'the guideline of heat disorders prevention in daily life' by Japanese Society of Biometeorology," Japanese Journal of Clinical Medicine, vol. 70, no. 6, pp. 1033-1038, 2012 (Japanese).

[12] G. S. Martinez, C. Imai, and K. Masumo, "Local heat stroke prevention plans in Japan: characteristics and elements for public health adaptation to climate change," International Journal of Environmental Research and Public Health, vol. 8, no. 12, pp. 4563-4581, 2011.

[13] L. E. Armstrong, Y. Epstein, J. E. Greenleaf et al., "American College of Sports Medicine position stand. Heat and cold illnesses during distance running," Medicine and Science in Sports and Exercise, vol. 28, no. 12, pp. 1-9, 1996.

[14] K. Parsons, "Heat stress standard ISO 7243 and its global application," Industrial Health, vol. 44, no. 3, pp. 368-379, 2006.

[15] G. M. Budd, "Wet-bulb globe temperature (WBGT)-its history and its limitations," Journal of Science and Medicine in Sport, vol. 11, no. 1, pp. 20-32, 2008.

[16] A. Hoshi, Y. Inaba, and K. Murayama, "Characteristics of incidence of heat disorders in Tokyo and Chiba-shi," Japanese Journal of Biometeorology, vol. 44, pp. 3-11, 2007 (Japanese).

[17] K. Zhang, Y. Li, J. D. Schwartz, and M. S. O’Neill, “What weather variables are important in predicting heat-related mortality? A new application of statistical learning methods," Environmental Research, vol. 132, pp. 350-359, 2014.

[18] A. Hoshi, S. Nakai, E. Kaneda, T. Yamamoto, and Y. Inaba, "Regional characteristics in the death due to heat disorders in Japan," Japanese Journal of Biometeorology, vol. 47, pp. 175-184, 2010 (Japanese with English Abstract).

[19] http://www.jma-net.go.jp/kofu/menu/kikou.html.

[20] 2015, http://www.pref.yamanashi.jp/english/profile/index.html.

[21] 2015, http://www.data.jma.go.jp/obd/stats/etrn/index.php.

[22] 2015, http://www.wbgt.env.go.jp.

[23] M. Ono and M. Tonouchi, "Estimation of wet-bulb globe temperature using generally measured meteorological indices," Japanese Journal of Biometeorology, vol. 50, pp. 147-157, 2010 (Japanese).

[24] M. Ono, "Global warming and heat disorders," Global Environmental Research, vol. 14, pp. 263-270, 2009 (Japanese).

[25] S. Nakai, A. Yorimoto, and T. Morimoto, "Environmental temperature of an athletic field in japan and comparison between wet bulb temperature and wbgt (wet bulb globe temperature)," Japanese Journal of Physical Fitness and Sports Medicine, vol. 39, no. 2, pp. 120-125, 1990 (Japanese).

[26] S. Akatsuka, T. Uno, and M. Horiuchi, "Regional characteristics of heat disorder incidence in Yamanashi Prefecture," Japanese Journal of Biometeorology, vol. 51, pp. 23-36, 2014 (Japanese).

[27] K. E. Smoyer, D. G. C. Rainham, and J. N. Hewko, "Heat-stressrelated mortality in five cities in Southern Ontario: 1980-1996," International Journal of Biometeorology, vol. 44, no. 4, pp. 190197, 2000.

[28] K. L. Bassil, D. C. Cole, R. Moineddin et al., "Temporal and spatial variation of heat-related illness using 911 medical dispatch data," Environmental Research, vol. 109, no. 5, pp. 600606, 2009.

[29] S. L. Harlan, A. J. Brazel, L. Prashad, W. L. Stefanov, and L. Larsen, "Neighborhood microclimates and vulnerability to heat stress," Social Science \& Medicine, vol. 63, no. 11, pp. 2847-2863, 2006. 
[30] W. Yu, K. Mengersen, W. Hu, Y. Guo, X. Pan, and S. Tong, "Assessing the relationship between global warming and mortality: lag effects of temperature fluctuations by age and mortality categories," Environmental Pollution, vol. 159, no. 7, pp. 17891793, 2011.

[31] B. G. Anderson and M. L. Bell, "Weather-related mortality: how heat, cold, and heat waves affect mortality in the United States," Epidemiology, vol. 20, no. 2, pp. 205-213, 2009. 

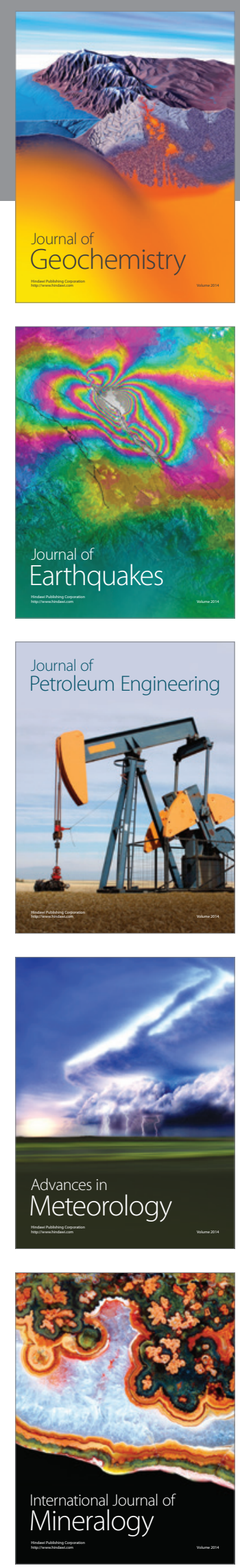
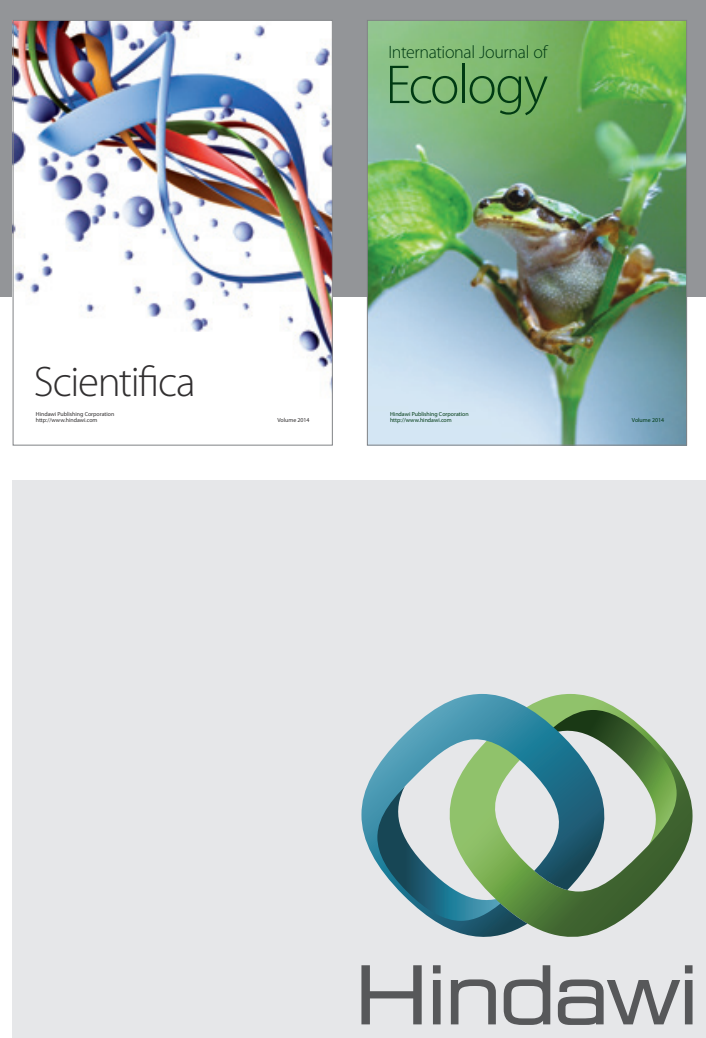

Submit your manuscripts at

http://www.hindawi.com
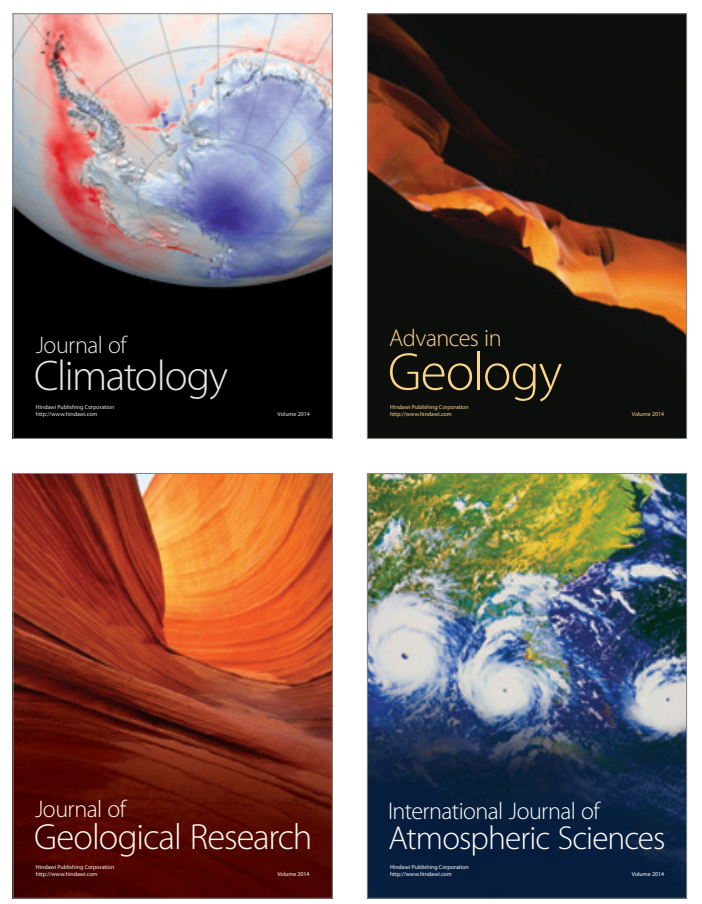

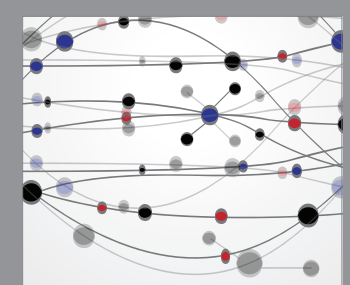

The Scientific

\section{World Journal}
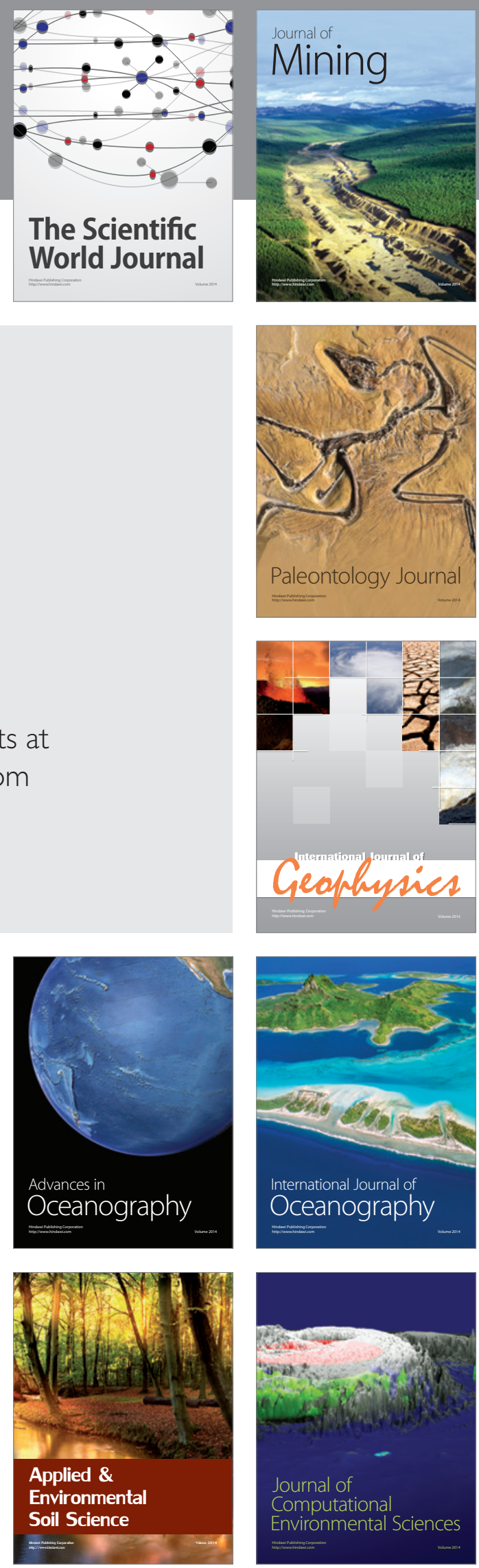